\title{
The burden of gunshot injuries on orthopaedic healthcare resources in South Africa
}

\author{
C Martin, ${ }^{1} \mathrm{MD}$, MSc; G Thiart, ${ }^{2} \mathrm{MB} \mathrm{ChB}$; G McCollum, ${ }^{2} \mathrm{MB}$ ChB, MMed, FC Ortho; S Roche, ${ }^{2} \mathrm{MB}$ ChB, $\mathrm{MMed}, \mathrm{FC}$ Ortho; \\ S Maqungo, ${ }^{2} \mathrm{MB} \mathrm{ChB}, \mathrm{MMed}, \mathrm{FC}$ Ortho \\ ${ }^{1}$ Department of Orthopaedics, School of Medicine, University of Texas Health San Antonio, USA \\ ${ }^{2}$ Department of Orthopaedic Surgery, Groote Schuur Hospital and Faculty of Health Sciences, University of Cape Town, South Africa
}

Corresponding author: C Martin (casewmartin@gmail.com)

\begin{abstract}
Background. Injuries inflicted by gunshot wounds (GSWs) are an immense burden on the South African (SA) healthcare system. In 2005, Allard and Burch estimated SA state hospitals treated approximately 127000 firearm victims annually and concluded that the cost of treating an abdominal GSW was approximately USD1 467 per patient. While the annual number of GSW injuries has decreased over the past decade, an estimated 54870 firearm-related injuries occurred in SA in 2012. No study has estimated the burden of these GSWs from an orthopaedic perspective.

Objective. To estimate the burden and average cost of treating GSW victims requiring orthopaedic interventions in an SA tertiary level hospital. Methods. This retrospective study surveyed more than 1500 orthopaedic admissions over a 12-month period (2012) at Groote Schuur Hospital, Cape Town, SA. Chart review subsequently yielded data that allowed analysis of cost, theatre time, number and type of implants, duration of admission, diagnostic imaging studies performed, blood products used, laboratory studies ordered and medications administered.

Results. A total of 111 patients with an average age of 28 years (range 13 - 74) were identified. Each patient was hit by an average of 1.69 bullets (range 1 - 7). These patients sustained a total of 147 fractures, the majority in the lower extremities. Ninety-five patients received surgical treatment for a total of 135 procedures, with a cumulative surgical theatre time of $>306$ hours. Theatre costs, excluding implants, were in excess of USD94 490. Eighty of the patients received a total of 99 implants during surgery, which raised theatre costs an additional USD53 381 cumulatively, or USD667 per patient. Patients remained hospitalised for an average of 9.75 days, and total ward costs exceeded USD130 400. Individual patient costs averaged about USD2 940 (ZAR24 945) per patient.

Conclusion. This study assessed the burden of orthopaedic firearm injuries in SA. It was estimated that on average, treating an orthopaedic GSW patient cost USD2 940, used just over 3 hours of theatre time per operation, and necessitated a hospital bed for an average period of 9.75 days. Improved understanding of the high incidence of orthopaedic GSWs treated in an SA tertiary care trauma centre and the costs incurred will help the state healthcare system better prioritise orthopaedic trauma funding and training opportunities, while also supporting cost-saving measures, including redirection of financial resources to primary prevention initiatives.
\end{abstract}

S Afr Med J 2017;107(7):626-630. DOI:10.7196/SAMJ.2017.v107i7.12257

Morbidity and mortality attributed to gunshot wounds (GSWs) are an immense burden on South African (SA) society and healthcare resources. Although annual homicides have decreased considerably over the past two decades, SA still faces a high rate of homicides and firearm-related violence. In 2012, SA ranked the 11th most deadly country in the world according to the United Nations Office on Drugs and Crime (UNODC), with a homicide rate of 31.1 per 100000 (Table 1). Cape Town in particular is violent, with 41 homicides per 100000 people in 2010. ${ }^{[1]}$ According to UNODC, the proportion of all homicides involving firearms in SA is about $45 \%$. The SA Police Service recorded 16259 homicides throughout the country in its 2012 - 2013 annual report, ${ }^{[2]}$ meaning that approximately 7317 homicides were firearm-related. Consequently, SA averages just over 20 gun-related homicides per day and has an annual rate of 14.0 gunrelated homicides per 100000 people (Table 2).

While the mortality rate attributable to firearms in SA is high, the burden of non-fatal firearm-related injuries is far worse. The SA government has not released disaggregated statistics on violent crime involving firearms or gun-related injuries in over a decade. Additionally, SA lacks a public national injury surveillance system to track fatal and non-fatal firearm injuries. Without these data, researchers must estimate the number of non-fatal GSWs in SA. Accordingly, Allard and Burch ${ }^{[4]}$ posited that 127000 non-fatal GSWs occurred per annum across the country in 2005. However, the passage and implementation of the Firearms Control Act in the early 2000 s led to a significant decrease in firearm violence and injuries, as evidenced by studies at individual hospitals. ${ }^{[5]}$

An updated national estimate for the annual number of non-fatal GSWs can be obtained by utilising SA's public homicide data and statistics from countries with national surveillance systems for fatal and non-fatal firearm injuries. The USA, which has six times as many citizens as SA, reported 11208 firearm-related homicides ${ }^{[6]}$ and 84258 non-fatal GSWs in $2013 .{ }^{[7]}$ Applying the ratio in the USA of approximately one firearm homicide to 7.5 non-fatal gunshot injuries to SA's approximately 7317 firearm homicides, it can be estimated that SA had over 54870 firearm-related injuries in 2012, a rate of $\sim 105$ GSWs per 100000 people. In other words, an estimated just over one out of every 1000 people in SA sustained a non-fatal GSW in 2012.

Quantifying the burden of these firearm injuries on society has been difficult. Allard and Burch ${ }^{[4]}$ calculated that treating abdominal GSWs cost USD1 467 per patient based on 21 patients who required 
Table 1. National firearm homicide and ownership rates*

\begin{tabular}{|c|c|c|c|c|c|c|}
\hline Country & $\begin{array}{l}\text { Total homicides } \\
\text { by guns, } n\end{array}$ & $\begin{array}{l}\text { Rate of homicides } \\
\text { by guns, per } \\
100000 \text { people } \\
\end{array}$ & $\begin{array}{l}\text { Homicides by } \\
\text { guns, \% }\end{array}$ & $\begin{array}{l}\text { Total civilian } \\
\text { guns, } n\end{array}$ & $\begin{array}{l}\text { Guns per } 100 \\
\text { people, } n\end{array}$ & $\begin{array}{l}\text { Rank by rate of } \\
\text { ownership }\end{array}$ \\
\hline Brazil & 34678 & 18.1 & 70.8 & 14840000 & 8.0 & 75 \\
\hline Colombia & 12539 & 27.1 & 81.1 & 2700000 & 5.9 & 91 \\
\hline Mexico & 11309 & 10.0 & 54.9 & 15500000 & 15.0 & 42 \\
\hline Venezuela & 11115 & 39.0 & 79.5 & 2850000 & 10.7 & 59 \\
\hline USA & 9960 & 3.2 & 67.5 & 270000000 & 88.8 & 1 \\
\hline Philippines & 7349 & 8.9 & 49.9 & 3900000 & 4.7 & 105 \\
\hline South Africa & $7317^{\dagger}$ & $14.0^{+}$ & 45.0 & 5950000 & 12.7 & 50 \\
\hline
\end{tabular}

Table 2. National firearm homicide rates

\begin{tabular}{ll} 
Table 2. National firearm homicide rates \\
\hline Country/territory & $\begin{array}{l}\text { Homicides by guns, } \\
\text { per } \mathbf{1 0 0} 000 \text { people }\end{array}$ \\
\hline Honduras & 68.4 \\
El Salvador & 39.9 \\
Jamaica & 39.4 \\
Venezuela & 39.0 \\
Guatemala & 34.8 \\
Saint Kitts and Nevis & 32.4 \\
Trinidad and Tobago & 27.3 \\
Colombia & 27.1 \\
Belize & 21.8 \\
Puerto Rico & 18.3 \\
Brazil & 18.1 \\
Dominican Republic & 16.3 \\
Panama & 16.2 \\
Bahamas & 15.4 \\
South Africa & $\mathbf{1 4 . 0 ^ { * }}$ \\
${ }_{\text {*Recalculated from estimated } 2012 \text { South African firearm homicide total. Information }}$ \\
from other countries from 2009 and $2010^{.3}{ }^{*}$
\end{tabular}

hospital admission and emergency surgery. This cost represented an amount 13 times greater than the annual per capita government health expenditure. Utilising a different costing method, Norberg et al ${ }^{[8]}$ later determined that each GSW patient requiring admission for $>12$ hours cost an average of USD2 230 in 2009.

\section{Objective}

No estimates have been made to date to assess the overall burden of gunshot injuries in SA from an orthopaedic perspective. This study therefore sought to estimate the burden and average cost of treating GSW victims requiring orthopaedic interventions in an SA tertiary level hospital.

\section{Methods}

This retrospective study surveyed over 1500 orthopaedic trauma patient admissions at Groote Schuur Hospital (GSH) in Cape Town over a 12-month period in 2012. The study was approved by the GSH Human Research Ethics Committee (ref. no. HREC R039/2013). Patients with orthopaedic gunshot injuries were identified by reviewing all orthopaedic trauma surgery logs and inpatient ward records for all patients admitted to the orthopaedic trauma wards. The study excluded patients with spinal and isolated hand GSW injuries, as they often require different resources and receive care from teams other than the GSH orthopaedic trauma unit. A number of other orthopaedic GSW patients with incomplete documentation were also excluded from the study. Finally, the study did not include paediatric patients aged $<12$ years, as they received treatment at a different hospital.

This screening method identified 111 patients admitted for orthopaedic injuries due to GSWs. A subsequent folder review for each patient ascertained data on the following parameters: duration of hospital stay in each ward; theatre time; procedure types; number and types of implants used; diagnostic imaging performed; blood products used; laboratory studies ordered; and medications administered.

The GSH financial department assisted with cost analysis. SA's public health system, however, lacks a costing culture for individual patients. Instead, the hospital allocates collective budgets rather than disaggregated patient reimbursements to departments. Consequently the daily cost of care in each ward and the cost of theatre time per minute could not be established without auditing individual wards and the entire operating theatre, which was not feasible given the scope of this investigation. Additionally, the National Department of Health $(\mathrm{NDoH})$ has not published standard cost tables with daily ward costs and operating theatre costs per minute for some time. Both these measures are essential to establish the overall GSW burden on the health system. To calculate the ward cost per day and operating theatre cost per minute, we used the total anaesthesia time as the total theatre time for each procedure and then adjusted for inflation the NDoH's daily ward and standard operating theatre costs per minute cited by Allard and Burch. ${ }^{[4]}$

The GSH financial department provided all other costs. Implant costs for each patient were determined using billing receipts from implant companies provided by the hospital financial department. Imaging, blood products, laboratory and pharmaceutical costs were documented with nationally standardised pricing. Lastly, the study analysed all outpatient follow-up and included additional imaging and pharmaceutical costs associated with treating the GSWs. The study did not include labour costs, as it was not possible to monitor and equitably monetarise the time staff spent tending to each patient.

The SA rand (ZAR) was converted to the US dollar (USD) using the US government Treasury Department's published end-of-year exchange rate of ZAR8.485 to USD1.00 from 31 December 2012. ${ }^{[9]}$ 


\section{Results}

Using the aforementioned criteria, the study identified 111 patients with orthopaedic GSW injuries treated during 2012. Patients included consisted of 104 males and 7 females, with an average age of 28 years (range $13-74$ ). Each patient was struck by an average of 1.69 bullets (range $1-7$ ), and these patients sustained a total of 147 fractures. The majority of fractures occurred in the lower extremities, with $38.8 \%, 15.6 \%$ and $11.6 \%$ of the 147 fractures occurring in the femur, tibia, and fibula, respectively.

Ninety-five patients received surgical treatment for a total of 135 procedures, ranging from 1 to 11 procedures per patient and averaging 1.42 operations per patient (Table 3). Of these procedures, 112 were orthopaedic, 13 were orthopaedic with concurrent general or vascular surgery procedures, and 10 were other non-orthopaedic trauma procedures. These 135 operations required a cumulative surgical time of 220 hours 3 minutes and cumulative anaesthesia time of 306 hours 25 minutes. For the 112 exclusively orthopaedic procedures, the average anaesthesia time was 117 minutes, while surgical time averaged 79 minutes. Theatre costs, excluding implants, exceeded USD94 490. Of the 95 patients requiring surgery, 80 needed some form of implant. A total of 99 implants were placed, with an average of 1.24 implants per patient. Cumulatively, these implants cost USD53 381, or about USD667 per patient. Orthopaedic GSW patients stayed in wards for a total of 1082 days. The average patient stayed 9.75 days, with admission ranging between 1 and 65 days (Table 4). Total costs for ward admissions exceeded USD130 400. All patients received $\mathrm{X}$-rays, with an average of 11 per patient. Patients in the study also received a total of 20 full-body screening digital X-ray studies, 34 computed tomography (CT) scans and 16 CT angiograms. Sixty patients required laboratory blood tests and 76 received blood products. On average, each patient's imaging cost USD194, laboratory blood tests cost USD32, blood products cost USD297, and discharge medications cost USD18.

In total, the costs of treating the 111 patients exceeded USD326 000 (ZAR2.7 million), with individual patient costs rang- ing from USD305 to USD20 046, and an average of USD2 940 (ZAR24 945) per patient (Table 5).

\section{Discussion}

The retrospective method of data analysis did not allow investigators to capture data on all GSW patients for the specified time frame. No conclusions regarding the average number of orthopaedic GSW patients presenting in a specific time period can therefore be made. However, given the large sample size, the study results illustrate the average burden of treating one orthopaedic GSW patient.

This burden can be broadly divided into time and financial cost. Time can then be subcategorised into time spent in operating theatres and wards, as patients in each setting consume valuable resources, including material consumables, physical beds and nonmaterial labour. Procedures for patients required an average of nearly 2 hours of anaesthesia time. GSH has a total of 40 hours of emergency theatre time available on weekdays and 48 hours on weekends; these are overestimates, however, as the figures do not account for room preparation and turnover time between cases or for staffing shortages. An average orthopaedic GSW case therefore uses at least $5 \%$ of the total available emergency theatre time, which various surgical disciplines must share. The longest orthopaedic procedure took nearly $12 \%$ of the available daily theatre time, while the patient requiring the longest procedure was treated concurrently by orthopaedics and trauma surgery and occupied the theatre for $25 \%$ of the available daily theatre time. We also analysed hospital admissions for each patient based on length of stay in each ward. In total, orthopaedic GSW patients stayed in the hospital for an average of 9.75 days, with an average of 7.35 days on the orthopaedic ward.

In addition to the time burden, the study quantified the monetary cost associated with treating orthopaedic GSW patients at a public hospital in SA. Two different approaches can be used for a cost analysis: a micro-level analysis from the bottom up, or a gross topdown assessment. ${ }^{[10]}$ Considered more accurate, as it requires detailed summation of costs for all items associated with individual patients, micro-costing is a labour-intensive process. A top-down approach

Table 3. Operating theatre time (minutes)

\begin{tabular}{|c|c|c|c|c|c|c|}
\hline & \multicolumn{2}{|c|}{$\begin{array}{c}\text { All procedures } \\
(N=135 \text { surgical procedures })\end{array}$} & \multicolumn{2}{|c|}{$\begin{array}{l}\text { Orthopaedic procedures } \\
\text { ( } N=112 \text { surgical procedures) }\end{array}$} & \multicolumn{2}{|c|}{$\begin{array}{l}\text { Per surgically treated patient } \\
\qquad(N=95 \text { patients })\end{array}$} \\
\hline & Anaesthesia time & Surgical time & Anaesthesia time & Surgical time & Anaesthesia time & Surgical time \\
\hline Mean & 136 & 98 & 117 & 79 & 194 & 139 \\
\hline Median & 112 & 75 & 105 & 67.5 & 137.5 & 97.5 \\
\hline SD & 87.31 & 83.03 & 56.34 & 48.05 & 208.81 & 167.22 \\
\hline Minimum & 32 & 9 & 32 & 9 & 40 & 9 \\
\hline Maximum & 600 & 580 & 285 & 225 & 1777 & 1430 \\
\hline Total & 18385 & 13203 & 13063 & 8849 & 18385 & 13203 \\
\hline
\end{tabular}

Table 4. Hospital stay (days)

\begin{tabular}{|c|c|c|c|c|c|c|c|}
\hline Ward & Total & Min. & Max. & Mean & Median & SD & $\begin{array}{l}\text { Patients who } \\
\text { used ward, } n\end{array}$ \\
\hline Orthopaedic & 735 & 1 & 48 & 7.35 & 5 & 6.52 & 100 \\
\hline Trauma & 291 & 1 & 35 & 4.04 & 1 & 5.52 & 72 \\
\hline High care & 28 & 5 & 15 & 9.33 & 8 & 5.13 & 3 \\
\hline Intensive care unit & 28 & 1 & 10 & 4.00 & 3 & 3.51 & 7 \\
\hline Total & 1082 & 1 & 65 & 9.75 & 7 & 8.09 & 111 \\
\hline
\end{tabular}


Table 5. Costs of orthopaedic gunshot wound injuries per patient (USD), $N=111$ patients

\begin{tabular}{|c|c|c|c|c|c|c|c|c|}
\hline & $\begin{array}{l}\text { Total } \\
\text { treatment }\end{array}$ & $\begin{array}{l}\text { Surgical } \\
\text { procedure, } \\
n=95 \text { patients } \\
\text { (135 procedures) }\end{array}$ & $\begin{array}{l}\text { Implants, } \\
n=80 \\
\text { patients } \\
\text { (99 implants) }\end{array}$ & Inpatient & $\begin{array}{l}\text { Diagnostic } \\
\text { imaging }\end{array}$ & $\begin{array}{l}\text { Discharge } \\
\text { medications, } \\
n=108 \\
\text { patients }\end{array}$ & $\begin{array}{l}\text { Blood } \\
\text { products, } \\
n=76 \\
\text { patients }\end{array}$ & $\begin{array}{l}\begin{array}{l}\text { Laboratory } \\
\text { tests, } \\
n=60 \text { patients }\end{array} \\
\end{array}$ \\
\hline Mean & 2940 & 995 & 667 & 1175 & 194 & 18 & 297 & 32 \\
\hline Median & 2380 & 707 & 589 & 777 & 174 & 3 & 45 & 18 \\
\hline SD & 2675 & 1073 & 357 & 1092 & 118 & 62 & 742 & 39 \\
\hline Maximum & 20046 & 9133 & 1768 & 7211 & 716 & 594 & 4690 & 227 \\
\hline Minimum & 305 & 206 & 28 & 222 & 46 & 0 & 17 & 2 \\
\hline Total & 326324 & 94493 & 53381 & 130427 & 21583 & 1964 & 22563 & 1914 \\
\hline
\end{tabular}

divides institutional costs by the number of patients treated to derive an average cost per patient. Previous studies have shown a degree of variability between these two costing methods; one study on the cost of treating fractured femurs demonstrated a difference of $\sim 10 \%$ using both cost analysis methods. ${ }^{[1]]}$ Our study used a mixture of both the micro and gross approaches: theatre and ward costs represented top-down cost estimates and attributing all other items to individual patients epitomised micro-level analysis.

When assessing the cost of orthopaedic gunshot injuries, direct and indirect costs must also be considered. Direct costs include resources consumed by the patients during their treatment and are subcategorised into fixed and variable expenses. Fixed costs are more difficult to assess on an individual patient basis as they include costs associated with maintaining and running the hospital, such as heating, electricity, water, and sterilising surgical theatres. Investigators also included staff salaries in this category because of the difficulty associated with allocating labour costs to individual patients. Consequently, staff salaries and hospital maintenance costs are not reflected in the study's costing calculations. The study did, however, reflect variable costs, including consumables such as theatre and ward time, dressings, imaging, medications, blood products and laboratory tests.

The estimated cost per orthopaedic GSW patient is, however, an underestimate of the true total cost, as it reflected neither the fixed expenses nor indirect expenses, which consist of criminal justice expenses and the loss of productivity, tax revenue and personal earnings due to incapacity. SA's paucity of data on the total number of GSWs across the country complicates the process of calculating the total cost, including indirect expenses, of firearm injuries nationwide.

Costing calculations in SA are further complicated by the lack of financial detail. GSH, like other SA public hospitals, lacks a culture of itemised billing and rigorous cost analysis per patient and the government has not published standard cost tables in more than a decade. This lack of individual data was the greatest obstacle to the study. Consequently, adjusting the Allard and $\mathrm{Burch}^{[4]}$ methodology for inflation for theatre and ward costs provided the best available cost estimate excluding labour costs. The private sector's culture of maintaining itemised costs that include both personnel time and consumables used in treating individual patients may provide a more reliable cost estimate, ${ }^{[12]}$ but the private sector's quantity and acuity of GSW patients do not compare with those seen in a public regional referral hospital.

Complicating matters, SA's public health sector lacks the resources to treat these injuries, both in terms of manpower and finances. The country has 0.7 physicians per 1000 people, compared with an average of 3.2 per 1000 among nations in the Organization of Economic Cooperation and Development. SA has even fewer surgeons, with only seven trained surgical specialists per 100000 people. ${ }^{[13]}$ Of SA physicians, $30 \%$ serve the public sector while the other $70 \%$, including most specialists, work in the private sector. In 2012 the SA government allotted approximately USD13.8 billion to healthcare, and the country as a whole spent USD982 per capita on health expenses. Private health systems, however, accounted for most of this spending as public funding, which serves $>80 \%$ of the population, constituted only $48 \%$ of SA's total healthcare costs in 2012. ${ }^{[14]}$ Patients exclusively funded by SA public healthcare therefore annually cost the state approximately USD224 each. ${ }^{[15]}$

With an average cost per patient of USD2 940, orthopaedic GSW patients consequently cost the SA state about 13.1 times the national expense per person in the public health sector.

This high cost per patient occurs despite GSH's numerous costsaving measures. For example, not all patients receive laboratory tests. Most patients in the study were young and medically stable, and for many, ward haemoglobins were sufficient for theatre. Additionally the SA government minimises the cost of implants for each public hospital by using a national tender system among orthopaedic suppliers for intramedullary nails. The GSH orthopaedic department also reuses external fixator components, except for pins and wires inserted into patients. The re-use of components when possible and the tender system for intramedullary nails significantly decreases the cost per patient - the most expensive implants in the study were angular stable locking plates billed for every single component used, e.g. distal femur plates plus each locking screw. Despite these measures, implant costs remain relatively high at USD667 per patient and represented $36.1 \%$ of total theatre expenses. Blunt trauma costing estimates have produced comparable figures. For example, Parkinson et al. ${ }^{[10]}$ determined the average implant cost for patients involved in a motor vehicle crash as USD977, which represented $37.9 \%$ of total theatre expenses.

Unfortunately, this study could not calculate total pharmaceutical cost per patient because of billing system limitations. All inpatient drugs are aggregated with patients' daily admission ward costs, while discharge and outpatient medications are billed separately. Again, low pharmaceutical costs for patients can be attributed to the demographic of patients, as most patients required only pain medications, such as acetaminophen and tramadol, on discharge. Because most orthopaedic patients required only standard X-rays, imaging costs were also minimised.

The findings were compared with the Allard and Burch ${ }^{[4]}$ study, which assessed the average cost of surgically treating an abdominal GSW patient. Adjusted for inflation from 2003 to 2012, their average costs were ZAR17 053 compared with our average of ZAR24 945. The USD917 difference was similar to the average cost of implants used per orthopaedic patient. Therefore, the average general surgery GSW patient costs approximately the same to treat as an orthopaedic GSW patient, with the exception of the added implant costs. Using data 
from 2000, Lutge et al.$^{[11]}$ determined that the unit cost of treating a fractured femur, regardless of aetiology and including implants, was about ZAR12 637, which, when adjusted for inflation, is about ZAR26 035 - a figure similar to this study's average cost of treating any type of orthopaedic GSW injury.

Admittedly, numerous critiques may be levelled at this study. Most importantly, it was impossible to calculate the orthopaedic GSW case burden on labour from both a time and financial perspective. Additionally, the study was not able to assess and include the costs of sundries used to treat patients on initial presentation in the trauma emergency room. The averages used in the Allard and Burch ${ }^{[4]}$ study to calculate the ward costs per day and operating theatre cost per minute are outdated and may have changed significantly over the past 10 years. Finally, this study was unable to capture expenses for numerous sundries, such as rolls of plaster of Paris, used in the wards and outpatient clinics that may slightly increase the average cost per patient.

Ultimately, we felt that the study's financial values provided a representative estimate of the average financial burden of orthopaedic gunshot injuries. The study also highlighted an initial suspicion: that orthopaedic implants significantly raise the cost of treating GSW patients.

\section{Conclusions}

This study assessed costs of treating orthopaedic injuries associated with firearm injuries in SA. On average, treating an orthopaedic GSW patient costs USD2 940 and uses 194 minutes of theatre time, and the patient occupies a hospital bed for 9.75 days. These patients cost the SA public health sector over 13 times the national annual average expense per patient. When compared with previous estimates of the costs associated with non-orthopaedic GSW cases, treating orthopaedic GSW patients is significantly more expensive, with the cost of implants used in orthopaedics accounting for much of the increased expense. Consequently, reducing the cost of treating future orthopaedic GSW patients will require an emphasis on ways to decrease implant prices.

With a greater understanding of not only the high incidence of orthopaedic GSWs treated in an SA tertiary care trauma centre but also the costs incurred, the national healthcare system can better prioritise orthopaedic trauma funding and training opportunities while also supporting cost-saving initiatives, including the redirection of resources to primary prevention initiatives. While firearm violence has decreased over the past decade after the passage and implementation of the Firearms Control Act, further gains are possible with additional enforcement of existing laws and the implementation of new prevention measures at community and national levels.

Few studies have definitively determined the proportion of all GSW victims in SA who sustain orthopaedic injuries. Similarly, no studies have established the total number of orthopaedic GSW patients treated annually throughout SA. Establishing these figures would help to determine more accurately the annual cost of the burden of orthopaedic GSWs nationally. Additionally, comparative studies of the costs in SA versus those in other countries may help national healthcare systems better anticipate costs, advocate for primary prevention, and minimise orthopaedic trauma-associated expenditures.

Acknowledgements. The authors would like to thank the University of Cape Town, the Department of Orthopaedic Surgery, Groote Schuur Hospital, and its orthopaedic trauma unit, and the University of Texas Southwestern Medical Center and its Office of Global Health.

Author contributions. Conception and design: SM, SR, GM; data collection: CM, GT, SM; data analysis and interpretation: CM, GT; drafting article: CM, GT, SM; critical revision: all authors; final approval of article: all authors.

Funding. None.

Conflicts of interest. None.

1. United Nations Office on Drugs and Crime. Global Study on Homicide 2011: Trends, Context, Data. Vienna: UNODC, 2011. https://www.unodc.org/documents/data-and-analysis/statistics/Homicide/ Globa_study_on_homicide_2011_web.pdf (accessed 16 March 2016).

2. South African Police Service. Crime Statistics: April 2013 - March 2014. Pretoria: SAPS, 2014. http:// 2. South African Police Service. Crime Statistics: April 2013 - March 2014. Pretoria: SAPS, 2014. http://
www.saps.gov.za/resource_centre/publications/statistics/crimestats/2014/crime_stats.php (accessed 13 January 2016)

3. The Washington Post. Gun homicides and gun ownership by country. Washington, DC: The Washington Post, 2012. http://www.washingtonpost.com/wp-srv/special/nation/gun-homicidesownership/table/ (accessed 13 January 2016).

4. Allard D, Burch VC. The cost of treating serious abdominal firearm-related injuries in South Africa. S Afr Med J 2005;95(8):591-594

5. Small Arms Survey. Small Arms Survey 2012: Moving Targets. Cambridge: Cambridge University Press, 2012:97. http://dx.doi.org/10.1017/CBO9781139013925

6. Centers for Disease Control and Prevention. Mortality, All Homicides. http://www.cdc.gov/nchs/ fastats/homicide.htm (accessed 16 March 2016).

7. National Center for Injury Prevention and Control, Centers for Disease Control and Prevention. Nonfatal Injury Reports 2001 - 2014. Overall Firearm Gunshot Nonfatal Injuries and Rates per 100,000 - 2013, United States, All Races, Both Sexes, All Ages. https://webappa.cdc.gov/sasweb/ncipc/ 100,000 - 2013, United States, All Races, Both
nfirates2001.html (accessed 16 March 2016).

nfirates2001.html (accessed 16 March 2016).
8. Norberg J, Nilsson T, Eriksson A, Hardcastle T. The costs of a bullet - inpatient costs of firearm injuries in South Africa. S Afr Med J 2009;99(6):442-444.

9. Internal Revenue Service. Treasury Reporting Rates of Exchange as of December 31, 2012. https:// www.irs.gov/businesses/small-businesses-self-employed/treasury-reporting-rates-of-exchange-as-ofdecember-31-2012 (accessed 13 January 2016).

10. Parkinson F, Kent SJW, Aldous C, Oosthuizen G, Clarke D. The hospital cost of road traffic accidents at a South African regional trauma centre: A micro-costing study. Injury 2014;45(1):342-345. http:// dx.doi.org/10.1016/j.injury.2013.04.007

11. Lutge EE, Muirhead D. The epidemiology and cost of trauma to the orthopaedic department at a secondary-level hospital. S Afr J Surg 2005;43(3):74-77.

12. Bowman B, Stevens G, Seedat M, Snyman R. Costing injuries in South Africa: Preliminary results and challenges from a pilot study. Afr J Health Sci 2010;17(3-4):57-63.

13. Mazumdar T. Five billion people 'have no access to safe surgery'. BBC News, 27 April 2015. http://www. bbc.com/news/health-32452249 (accessed 16 March 2016).

14. Organization for Economic Cooperation and Development. OECD Health Statistics 2014: How does Organization for Economic Cooperation and Development. OECD Health Statistics 2014: How does
South Africa compare? http://www.oecd.org/els/health-systems/briefing-note-south-africa-2014.pdf

15. Keeton C. Bridging the gap in South Africa. Bull World Health Organ 2010;88(11):803-804. http:// dx.doi.org/10.2471/blt.10.021110

Accepted 21 February 2017. 